\title{
MULTI-CHIP MODULE TECHNOLOGY ${ }^{\dagger}$
}

\author{
R.A. RINNE and D.R. BARBOUR \\ IBM Corporation, Hopewell Junction, $N Y$ (USA)
}

(Received January 6, 1982; in final form March 22, 1982)

\begin{abstract}
The paper describes the key design features and outlines the manufacturing process for multi-chip ceramic modules used in recently announced IBM products. Emphasis is placed on the thermal conduction module (TCM) which is used in the IBM 3081 computer and incorporates the most advanced substrate and module technologies at IBM. The $90 \mathrm{~mm} \times 90 \mathrm{~mm}$ TCM substrate contains up to 32 ceramic layers and typically $130 \mathrm{M}$ of impedance controlled wiring to interconnect up to 118 LSI logic and array devices. The TCM is designed to provide a cooling capacity of up to $300 \mathrm{~W}$. Key manufacturing challenges are highlighted.
\end{abstract}

\section{INTRODUCTION}

As circuit densities are increased through achievements in semiconductors, there is a need to preserve and complement these improvements with improvements at the package level to provide the system designer with a technology that optimizes performance, reliability, and cost. At IBM, we have taken the path of multi-chip modules utilizing multi-layer ceramics to achieve these objectives.

IBM first introduced a multi-layer ceramic (MLC) multi-chip module (MCM) technology in 1979 in the 4300 series of intermediate processors. ${ }^{1,2}$

These modules, shown in Figure 1, are $35 \mathrm{~mm}$ square and $50 \mathrm{~mm}$ square and provide the capability to mount up to nine LSI chips providing a $2 \mathrm{X}$ increase in circuit or bit packaged density over previous single chip module designs. These packages have allowed for significant reductions in wiring length and the number of inter-package connections resulting in performance and reliability improvements.

The $35 \mathrm{~mm}$ and $50 \mathrm{~mm}$ modules use a substrate consisting of up to 22 ceramic metallized layers for interconnecting the LSI devices and I/O pins. Figure 2 illustrates the cross section. A typical $35 \mathrm{~mm}$ or $50 \mathrm{~mm}$ module can support 4000 circuits and provides a maximum cooling capability of $9 \mathrm{~W}$.

The most recently announced IBM multi-chip module design is the thermal conduction module (TCM) shown in Figure 3. This module, used in the IBM 3081 system, is approximately $150 \mathrm{~mm} \times 150 \mathrm{~mm} \times 60 \mathrm{~mm}$ in size and provides the capability to mount up to 100 LSI logic chips or up to 118 LSI logic and array chips. Typically, a TCM contains 25,000 logic circuits and 65,000 array bits. The TCM has been designed to handle thermal loads of up to 300 watts/module. It is constructed to be pluggable with 1800 simultaneous connections to a large organic printed circuit board by means of an IBM designed connector assembly.

The significance of the thermal conduction module coupled with LSI semiconductors is apparent considering that the TCM allows for a level of logic partitioning at the module level that was previously accomplished at the gate level. A typical TCM replaces many single chip modules, printed circuit cards and boards, and cables required in earlier IBM systems.

†This paper was originally presented orally at the Technical Session of Productronica in Munich, November, 1981. 


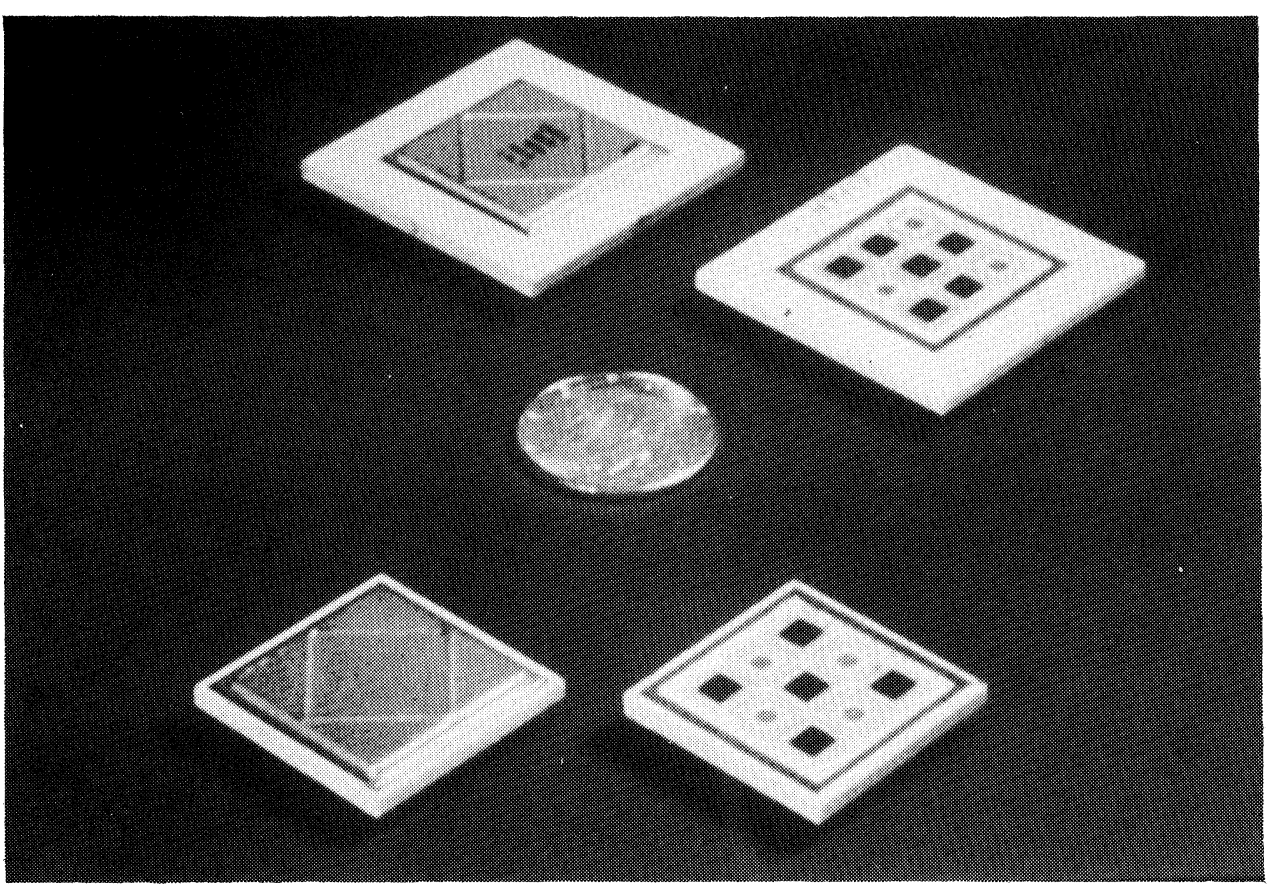

FIGURE $135 \mathrm{~mm}$ and $50 \mathrm{~mm}$ multichip modules

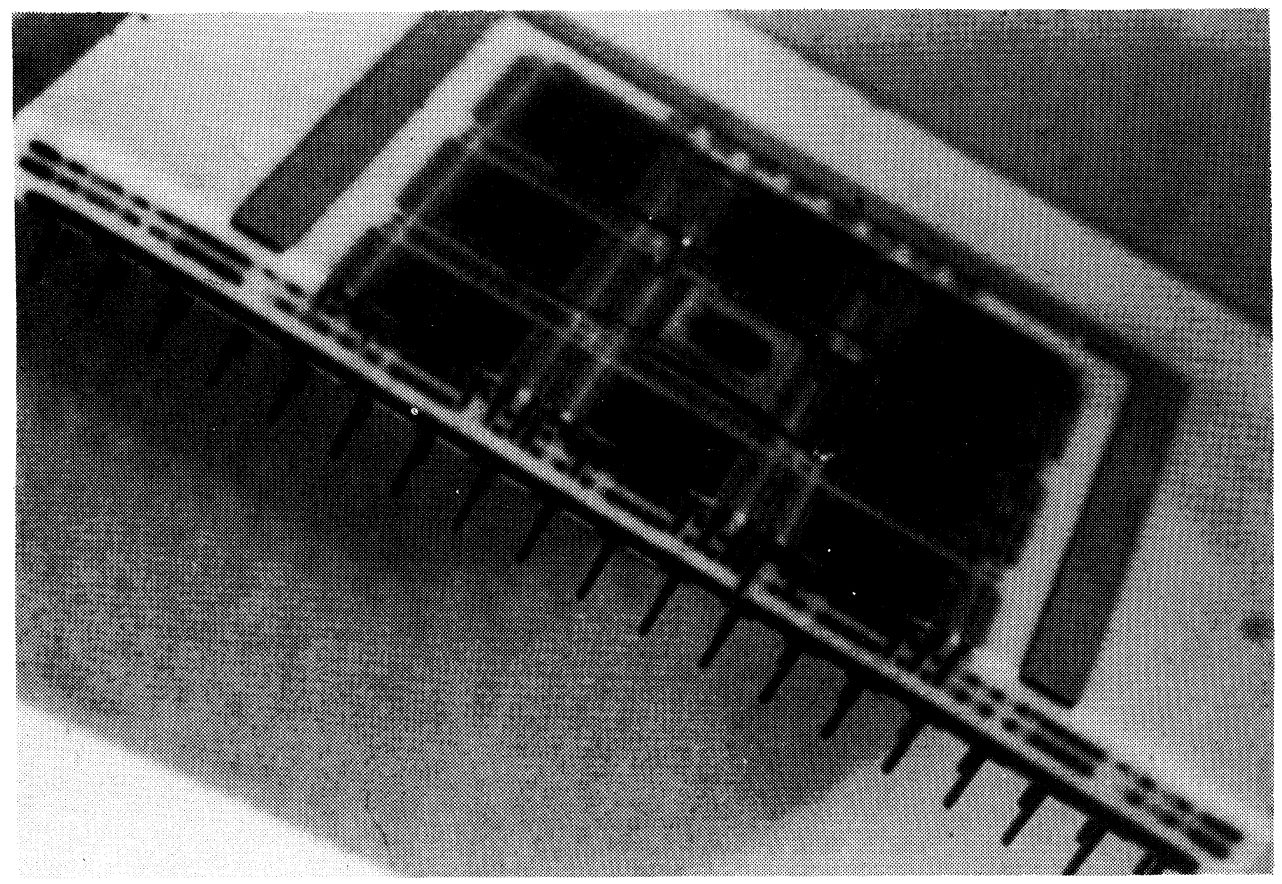

FIGURE $250 \mathrm{~mm}$ substrate cross section 


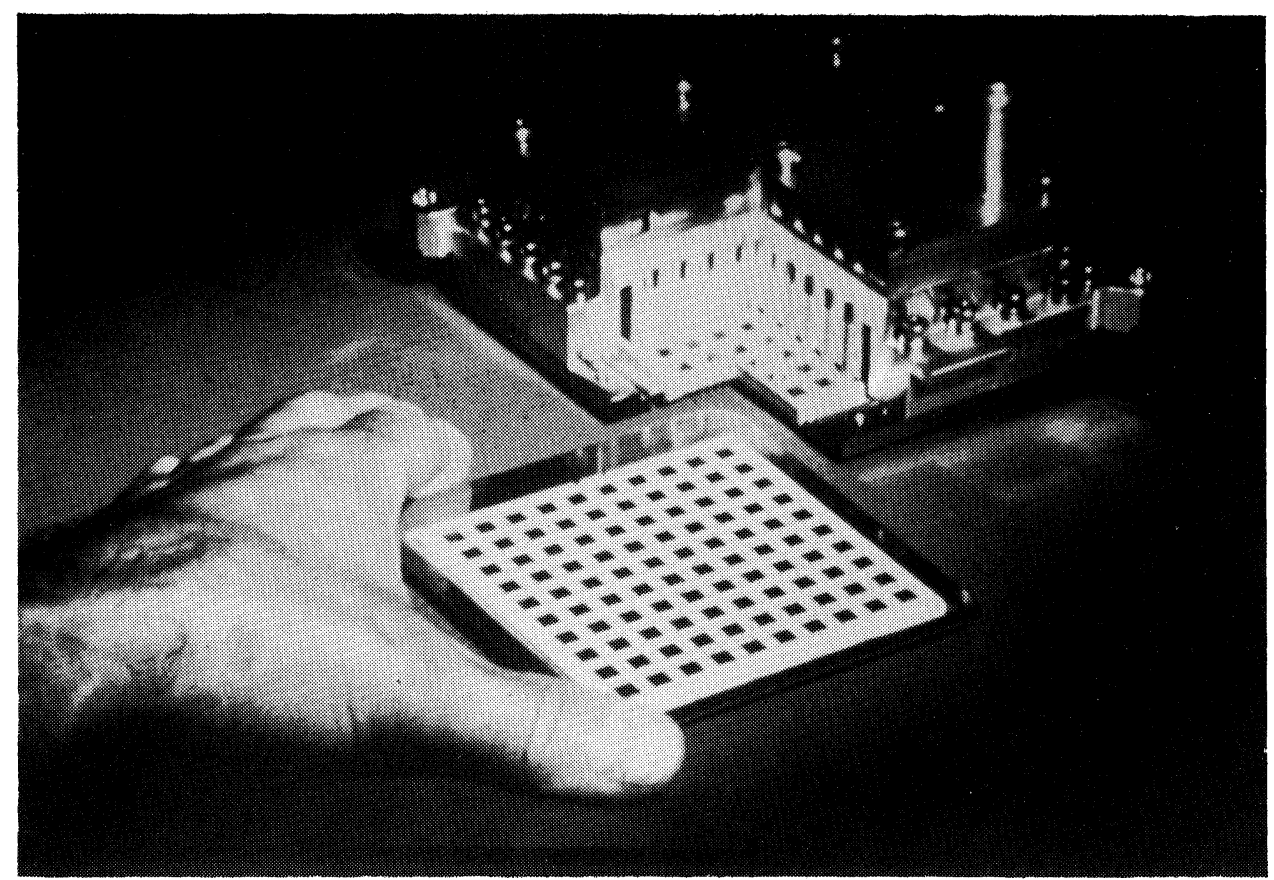

FIGURE 3 Thermal conduction module

The large reduction in hardware results in an order of magnitude reduction in packaging inter-level connections which results in a significant improvement in system reliability. Further, logic wiring length is reduced at all levels of packaging compared to earlier technologies. Wiring length reduction is a significant factor in performance improvement in the IBM system 3081.

\section{THERMAL CONDUCTION MODULE DESIGN}

The major components making up the TCM are shown in Figure 4.

A key element of the TCM is the multi-layer ceramic substrate which will be described in more detail later in this article. Mounted on the substrate are the LSI chips, in this case 100 logic chips.

A frame-like flange has been brazed to the substrate to facilitate assembly to the module cover.

Spring loaded pistons are fitted into the cover assembly. When assembled, these pistons rest against the back side of the LSI chips to provide a thermal path from the chips to the cover assembly.

The cover and substrate assembly are sealed together by compressing a "C" ring between the flange and cover utilizing the base plate.

After assembly, the module is charged with helium to enhance heat transfer to the cover and provide an inert environment to the semiconductor chips.

A water jacket is bolted to the top of the cover assembly to complete the thermal path.

The top surface of the substrate is designed for C-4 mounting of flip chips ${ }^{3}$ and for bonding of engineering change discrete wiring as shown in Figure 5. 


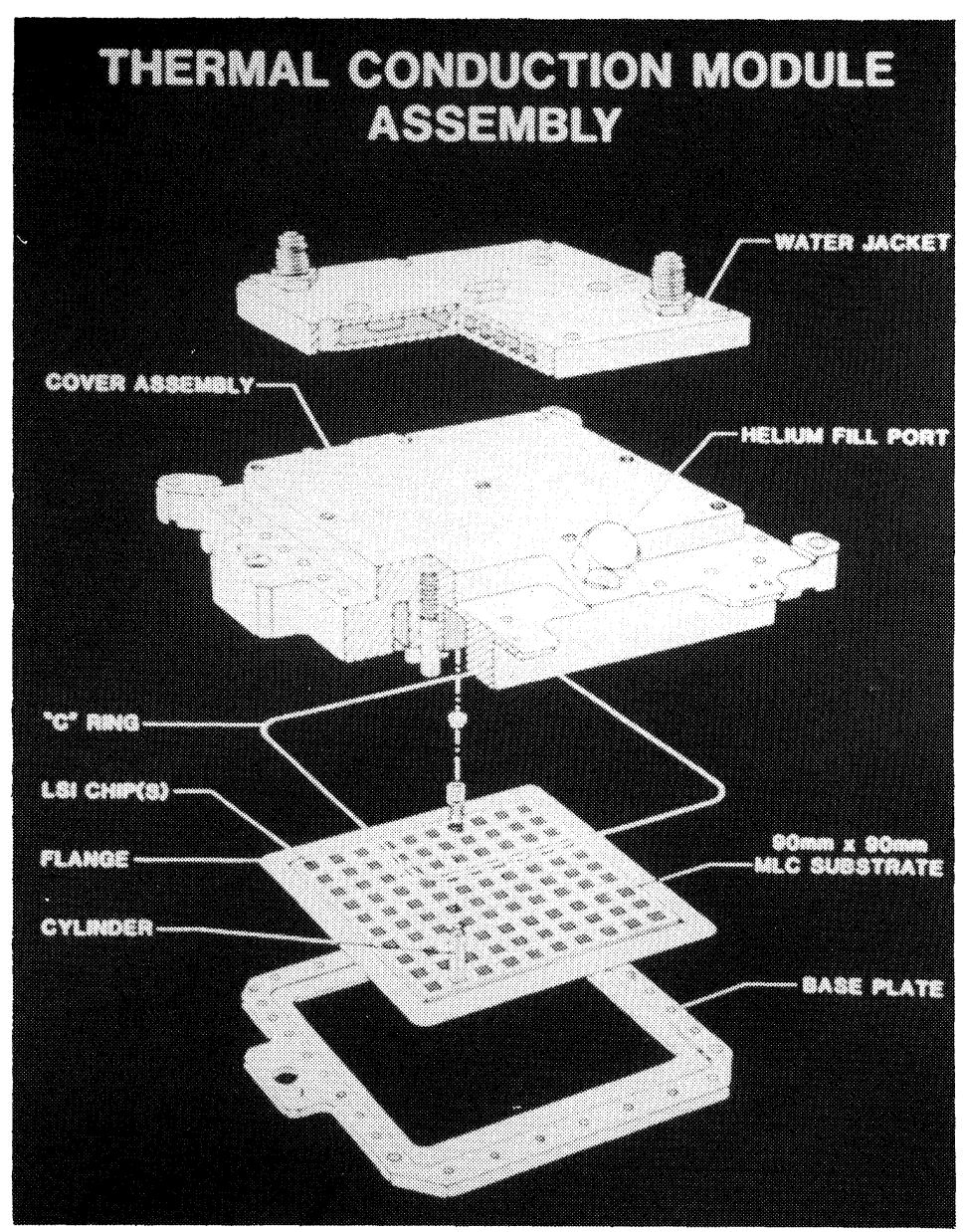

FIGURE 4 Thermal conduction module assembly

The uppermost layers in the substrate route connections from the C-4 pads to the discrete wire bond pads on the top surface and also distribute connections from these pads to the internal layers as illustrated in Figure 6. The central layers provide wiring for chip-to-chip and $\mathrm{I} / \mathrm{O}$ pin connections and are arranged in $\mathrm{x}-\mathrm{y}$ pairs for efficiency in wire routing. The bottom substrate layers are used for power distribution. Power and signal connections to the TCM are achieved through 1800 connector pins brazed to the bottom surface of the substrate. Figure 7 shows a cross-section of a TCM substrate. Figure 8 summarizes the key features of the TCM.

\section{SUBSTRATE FABRICATION}

The process includes raw material preparation, casting and blanking, punching, signal and voltage pattern screening, layer assembly and lamination, sintering, metal plating, electrical testing, and brazing of interconnection pins and mounting hardware.

One of the advantages of the MLC process is that the screened layers are produced in parallel rather than sequentially, allowing for sorting of defective layers prior to assembly. 


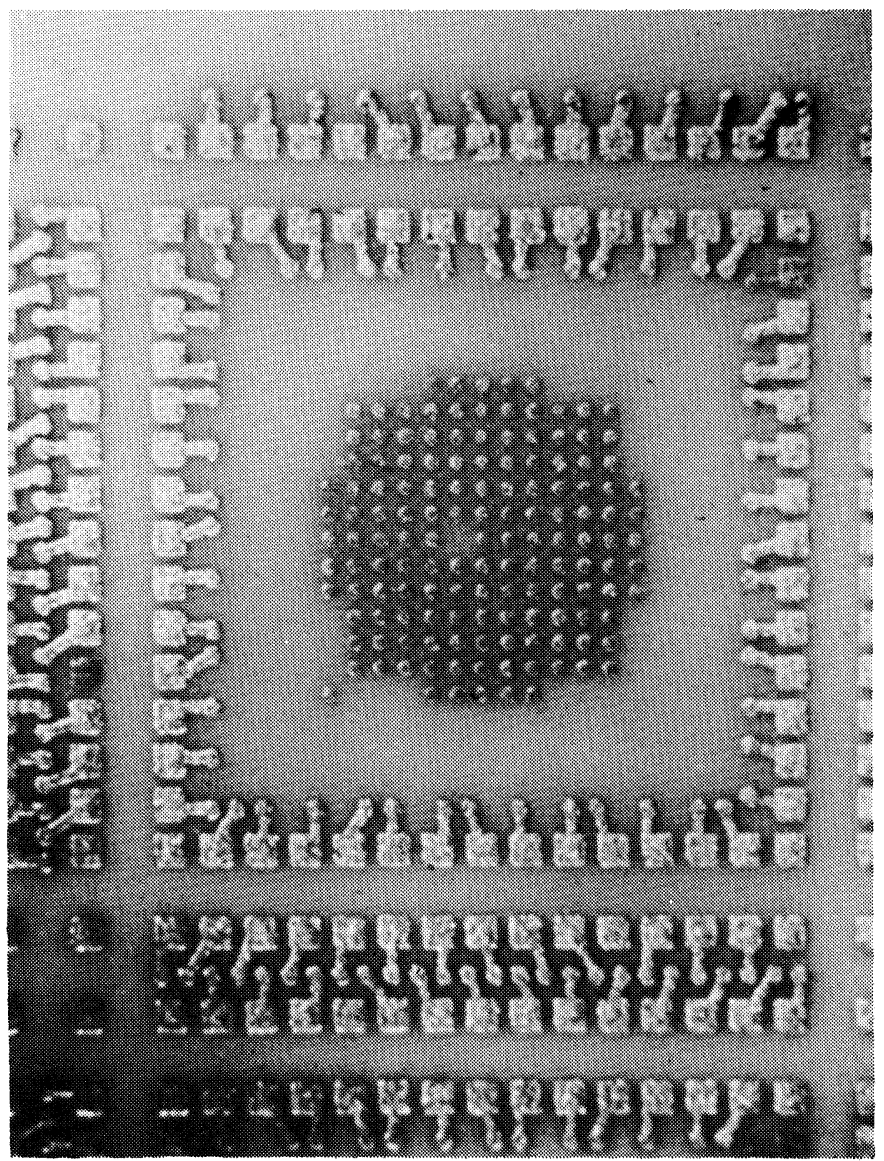

FIGURE 5 Top surface metallurgy

More broadly, the process consists of four major sectors: green sheet fabrication, personalization, substrate assembly, and substrate finishing and test.

\section{GREEN SHEET FABRICATION}

Green sheet fabrication starts with raw material preparation. The inorganic raw materials consist of alumina $\left(\mathrm{Al}_{2} \mathrm{O}_{3}\right)$ and a refractory glass $\left(\mathrm{SiO}_{2}\right)$ which acts as a sintering aid and provides desirable properties in the fired substrate. Batch to batch uniformity of these materials is critical to achieve a cast sheet with consistent properties and to control shrinkage during the sintering process. Prior to use, the alumina and glass are evaluated for properties such as particle size, composition, and purity, using analytical techniques.

The organic raw materials consist of resin, plasticizer, and solvents which are also analytically evaluated at incoming inspection. The organics are combined with the alumina and glass in a ball mill to form a uniform dispersion. Figure 9 is an illustration of the ball mill used for this process.

Following dispersion, the slurry is filtered to remove agglomerates and contaminants, and evaluated against specifications for viscosity and other properties. The slurry is transported in a mobile container designed to supply slurry directly to the caster. 


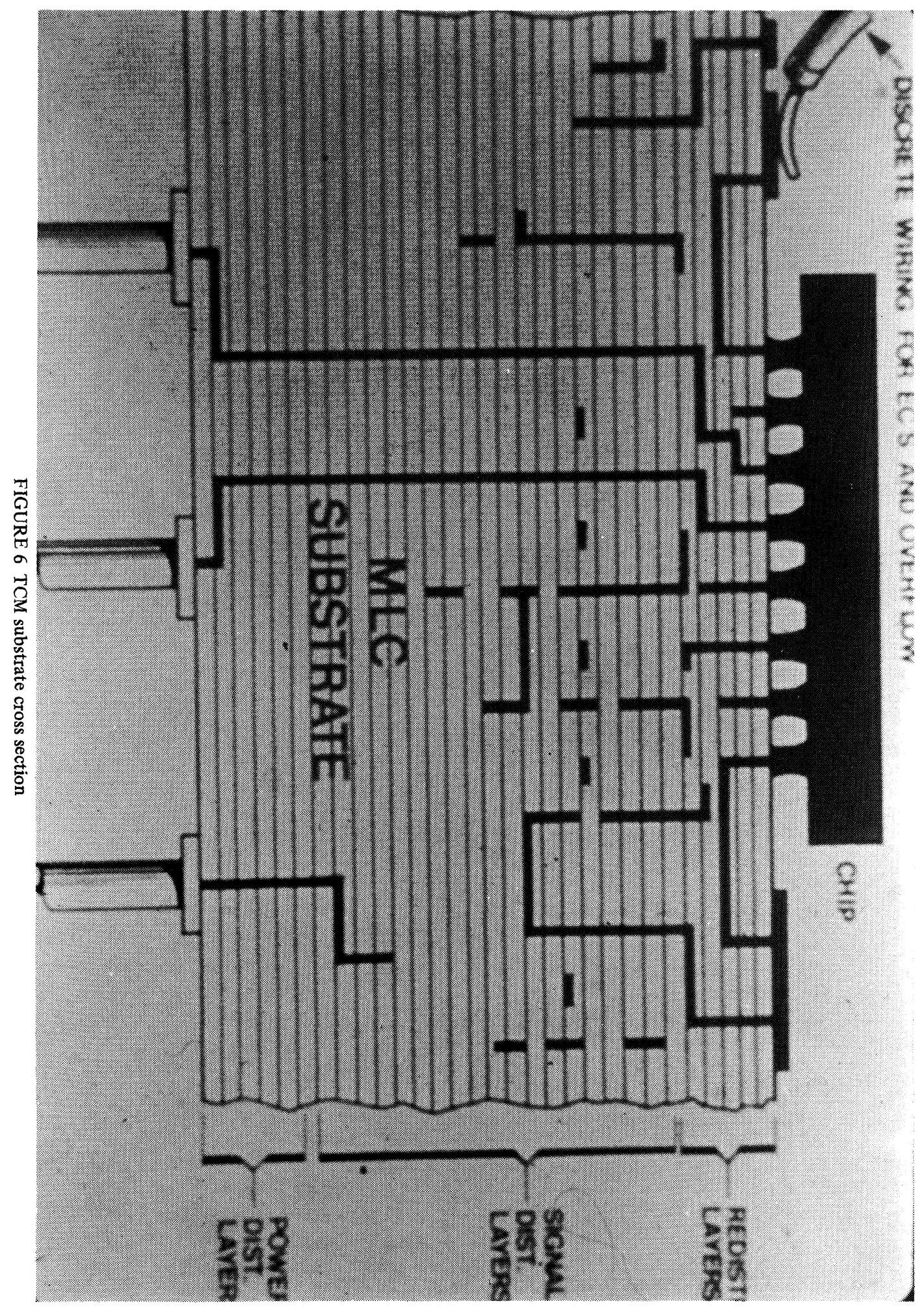




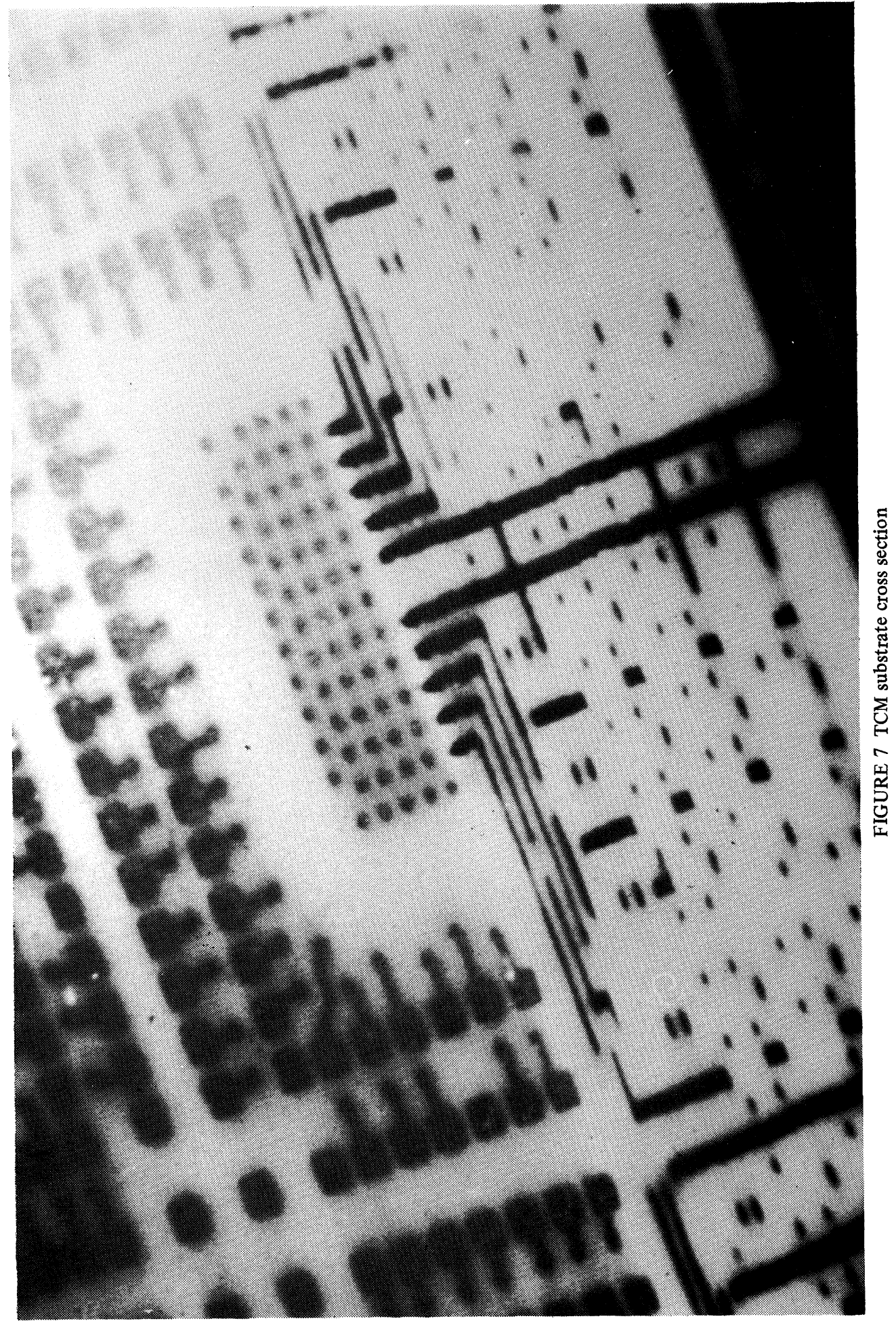




\section{TCM FEATURES}

\section{LAVERS}

350,000 VIAS

130 METERS WRE LENCTH

3,000 Wuane nETs

UP To 14,160 C-4 Jonts

1800 1/O PINS

EC OR OVEAFLOW WIRES

UP TO 118 LOCIC AND ARRAY CHIPS

25,000 CIRCUTS AND 65,000 EITs (TYPICAL) 300 WATTS

FIGURE 8 TCM features

\section{MILLING}

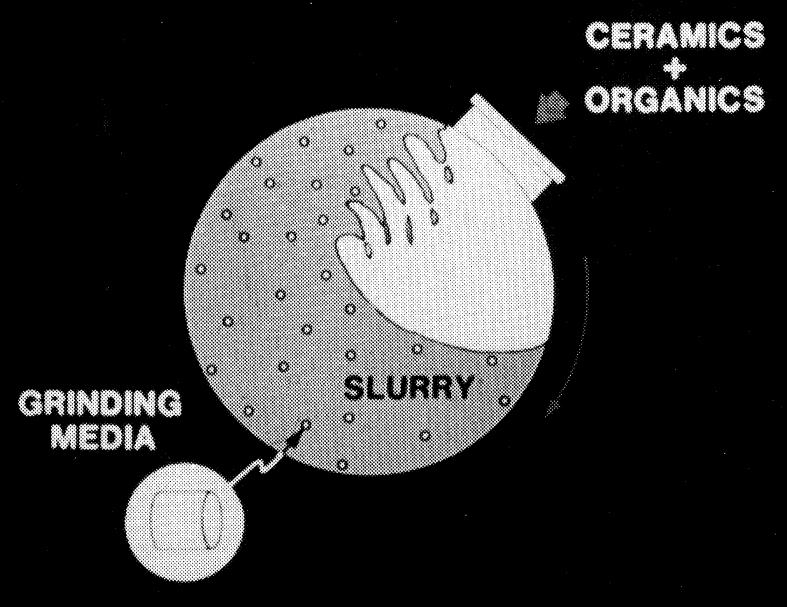

FIGURE 9 Raw material milling 
A continuous caster, equipped with a constant level slurry reservoir and doctor blade, forms $200 \mathrm{~mm}$ wide ceramic tapes on a constantly moving web. Ceramic thickness is controlled by the reservoir level and doctor blade setting as shown in Figure 10. Thickness is monitored in both the wet and dry state. The web passes through drying zones on the caster and is then separated from the film carrier and spooled.

Drying temperatures are controlled in addition to dryer air velocity and casting rate in order to provide a dry sheet with uniform binder distribution and other necessary properties. These parameters include proper compression set to assure metal line enclosure during lamination and a structure that is absorbent enough to provide sharply defined metal patterns during screening and yet is stable following metallization. The spool of ceramic tape is measured for thickness and optically inspected for defects such as tears, pin holes, and dirt. The tape is then cut into $185 \mathrm{~mm}$ square blanks as shown in Figure 11. These blanks are evaluated for green density, compressibility, bond strength, and tensile strength. A final evaluation involves lamination and firing of unmetallized layers to determine shrinkage and measurement of fired density.

\section{GREEN SHEET PERSONALIZATION}

Green sheet personalization, the next major process sector, consists of via hole punching and metallization.

IBM designed, computer controlled step and repeat equipment illustrated in Figure 12 is used to punch via holes in each substrate layer. A pallet used for mounting the green sheets, is an integral part of a precision $x-y$ table that moves the green sheet relative to a $\mathrm{x}-\mathrm{y}$ stationary multiple punch and die set operating at a high rate of speed. Four location holes position the ceramic layer over pins on the pallet. Punches sheets are inspected for

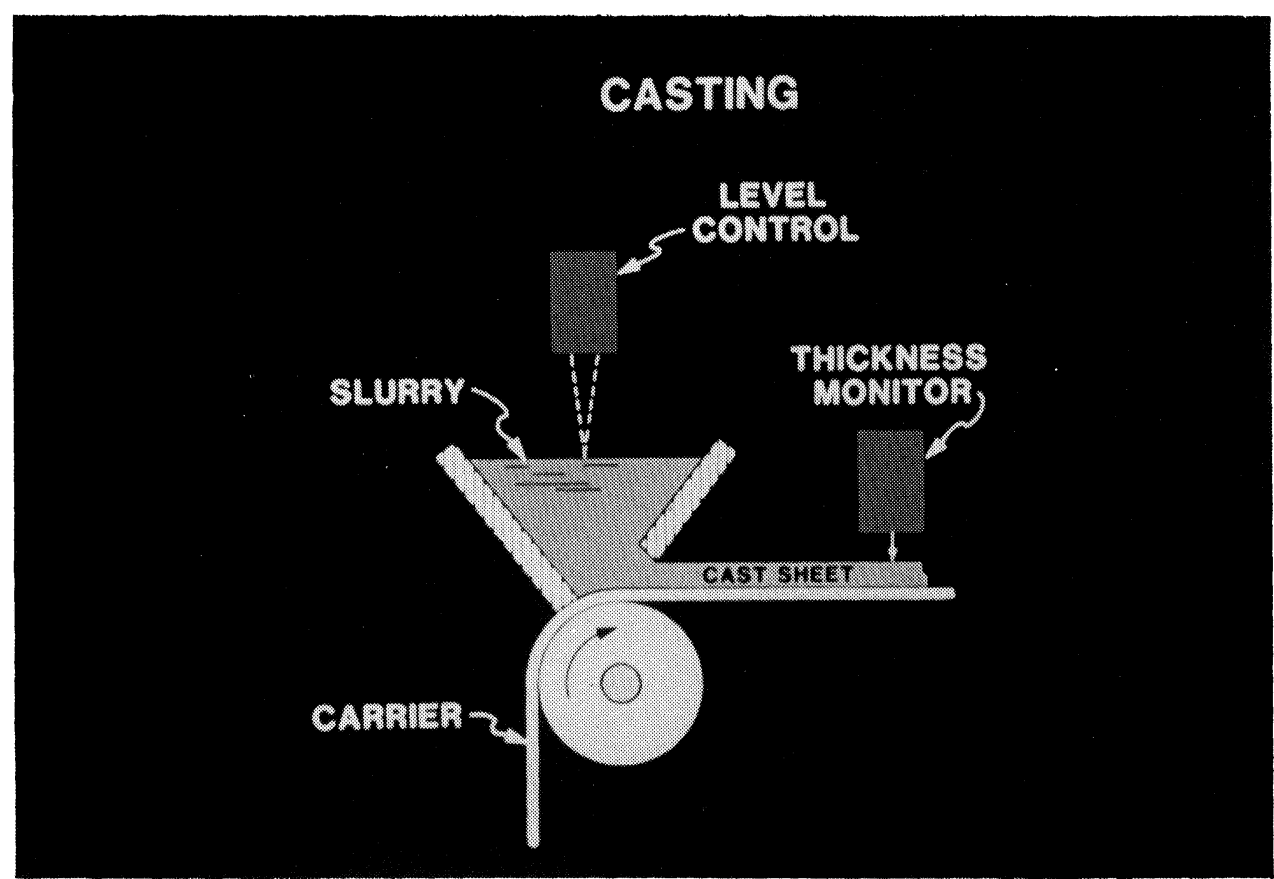

FIGURE 10 Casting 


\section{BLANKING}

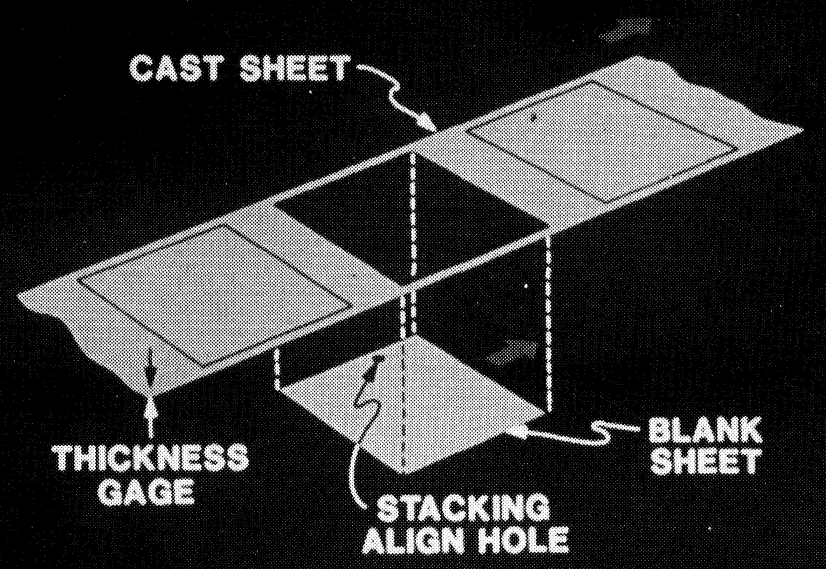

FIGURE 11 Blanking

\section{PUNCHING}

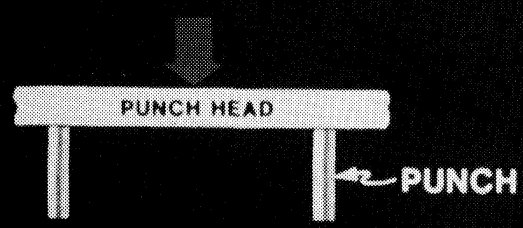

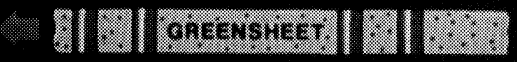

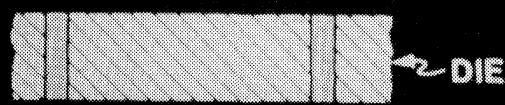

FIGURE 12 Punching 
hole location. Measurement is made from $x-y$ datums established by the corner locating holes. In addition, hole size is measured for correct dimensions and the punched sheets are optically inspected for defects.

Paste, used for metallizing the layers, consists of conductive powder uniformly mixed with a resin, solvent, and other additives. The composition is not the same for all layers and is selected to make the proper trade-off between conductivity, metal shrinkage, and screening properties. Likewise, the paste vehicle is varied to account for pattern differences and extent of metallization.

The equipment used for pattern screening is illustrated in Figure 13. The punched green sheet is positioned on the screener using the same four location holes used in punching. A traversing paste reservoir and nozzle assembly, an integral part of the screener, forces paste through a metal mask which is in direct contact with the green sheet, filling the via holes and defining the layer pattern.

The top surface pattern consists of metallized vias for C-4 (flip chip) to substrate connections. There is also an array of pads surrounding each chip site for electrical test and attachment of engineering change wiring. Typically, re-distribution, signal, and reference planes are screened with fine lines and spaces. Power planes are metallized over the total surface except for clearance rings surrounding vias where electrical isolation is needed. On the bottom layer there is an array of pads used for brazing $\mathrm{I} / \mathrm{O}$ pins in place.

Following screening, the metallized sheets are dried. The drying cycles have been optimized, and are carefully controlled to maintain required green sheet properties. Finally, the sheets are inspected with automatic equipment that defects deviations in the screened pattern.

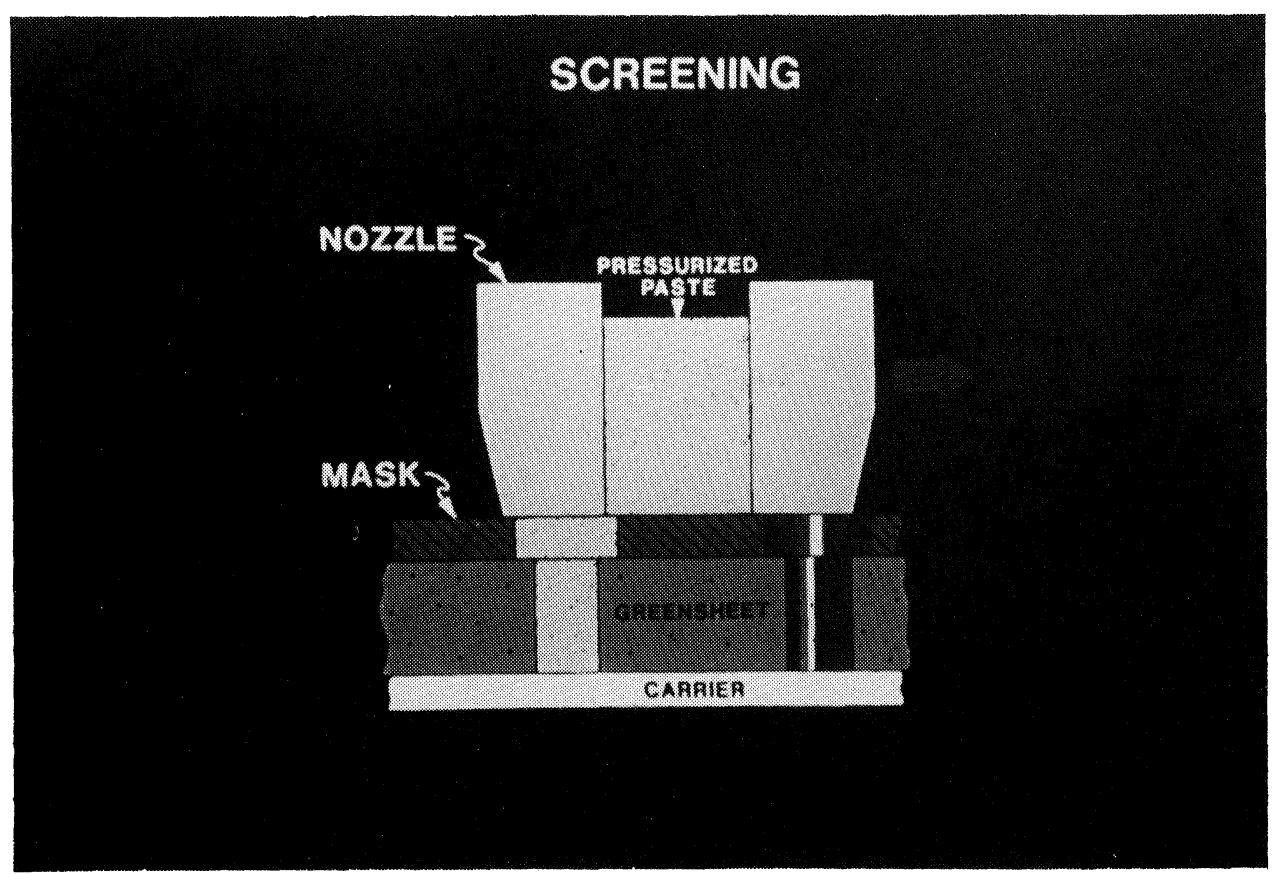

FIGURE 13 Screening 


\section{SUBSTRATE ASSEMBLY}

The third major process sector is substrate assembly.

Inspected layers are stacked on a pinned fixture using the four corner location holes in each green sheet as illustrated in Figure 14. The stacking fixture is mounted on a die which is an integral part of the lamination press. The lamination die is precision machined and assembled to assure parallelism and flatness which is critical to achieving uniform green density and shrinkage during sintering. Figure 15 illustrates the lamination operation. During lamination, the layers are sheared from the $185 \mathrm{~mm}^{2}$ stack and compressed.

The green laminate is cut with a carbide saw as shown in Figure 16. The laminate is aligned using an $x-y$ table and held in place with vacuum.

Figure 17 shows the substrates as they are sintered in batch kilns. During sintering the substrates are supported on suitable surfaces to achieve flatness and to assure uniform temperature throughout the sintering cycle. The firing process has been optimized to control shrinkage accurately which is needed to achieve the dimensional control for further processing. In addition, the sintering cycle has been defined to reach high densification of the ceramic-glass-metal composite.

During the initial phase of sintering in a hydrogen environment, residual solvents and the organic materials start to decompose. As temperature is increased, moisture is added to accelerate oxidation of residual carbon. Sintering and densification of the ceramic/ metal composite starts prior to reaching the peak temperature. A controlled cooling cycle follows to complete the process. A dramatic dimensional change occurs during sintering as illustrated in Figure 18. Each substrate is inspected for dimensions, flatness, and surface defects.

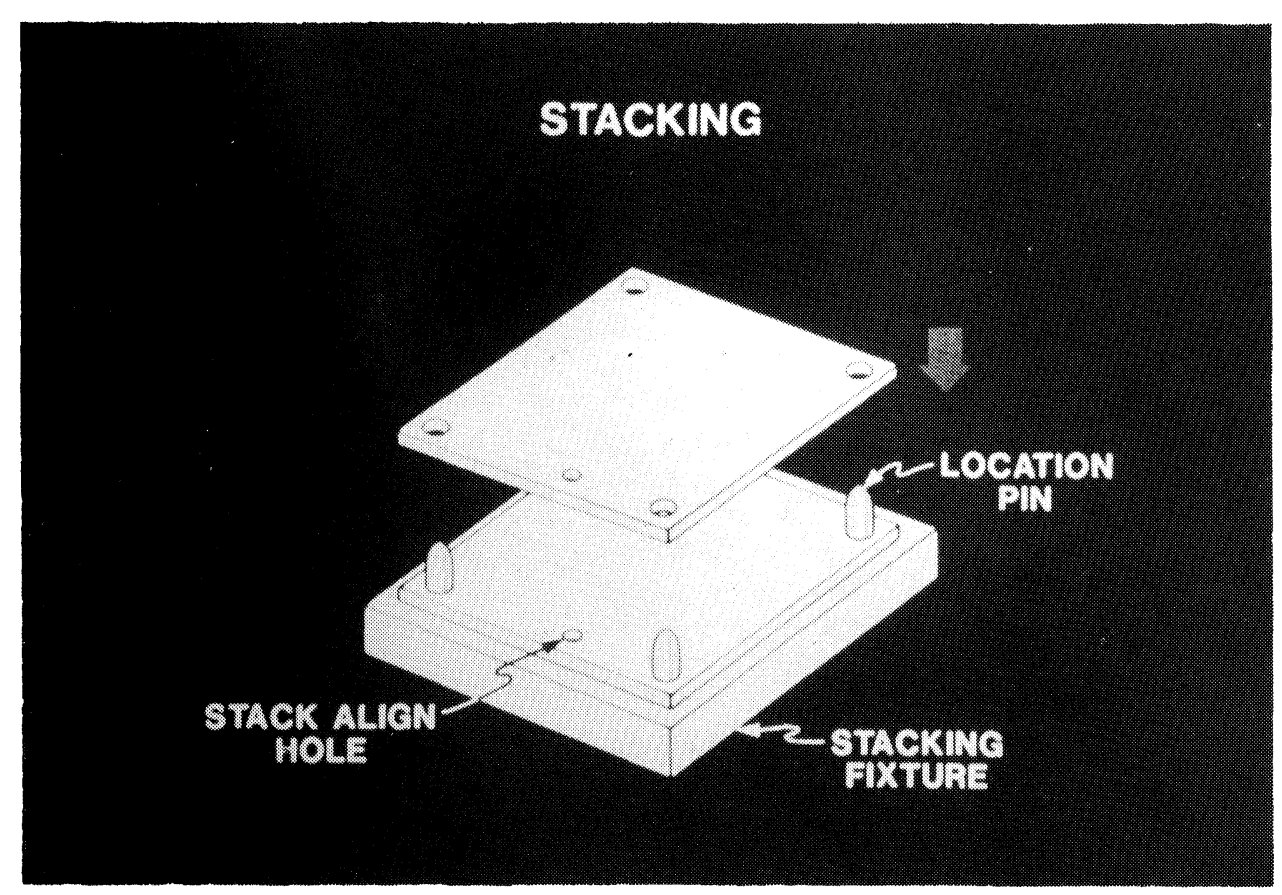

FIGURE 14 Stacking 


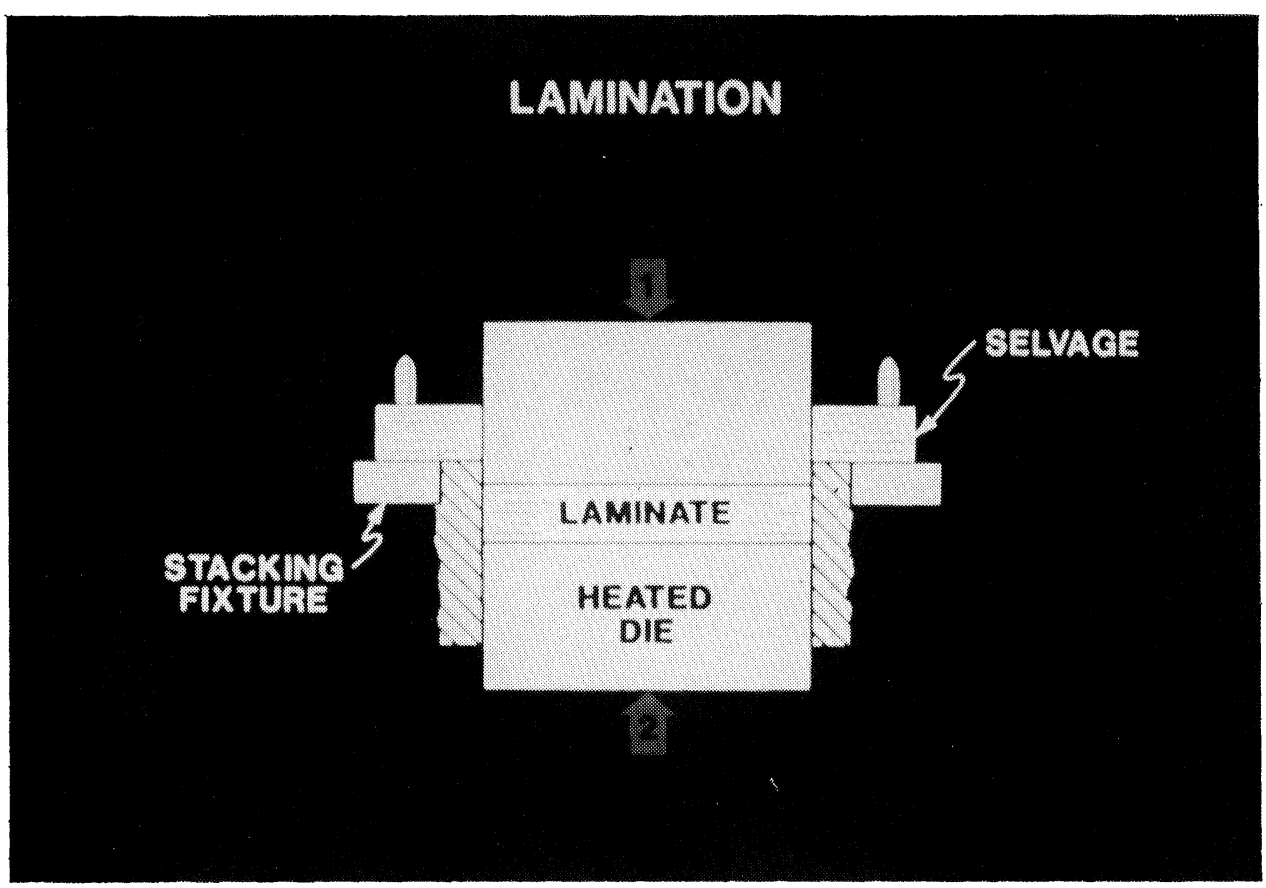

FIGURE 15 Lamination

\section{SIZING}

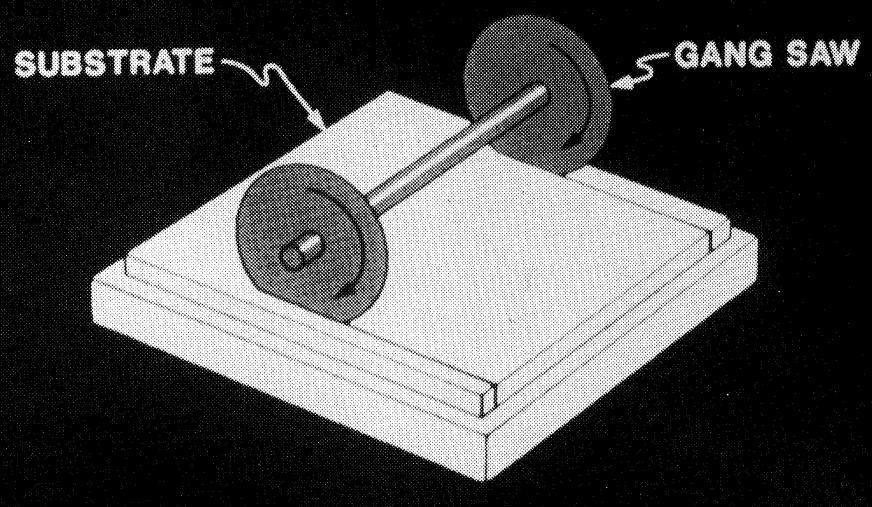

FIGURE 16 Sizing 


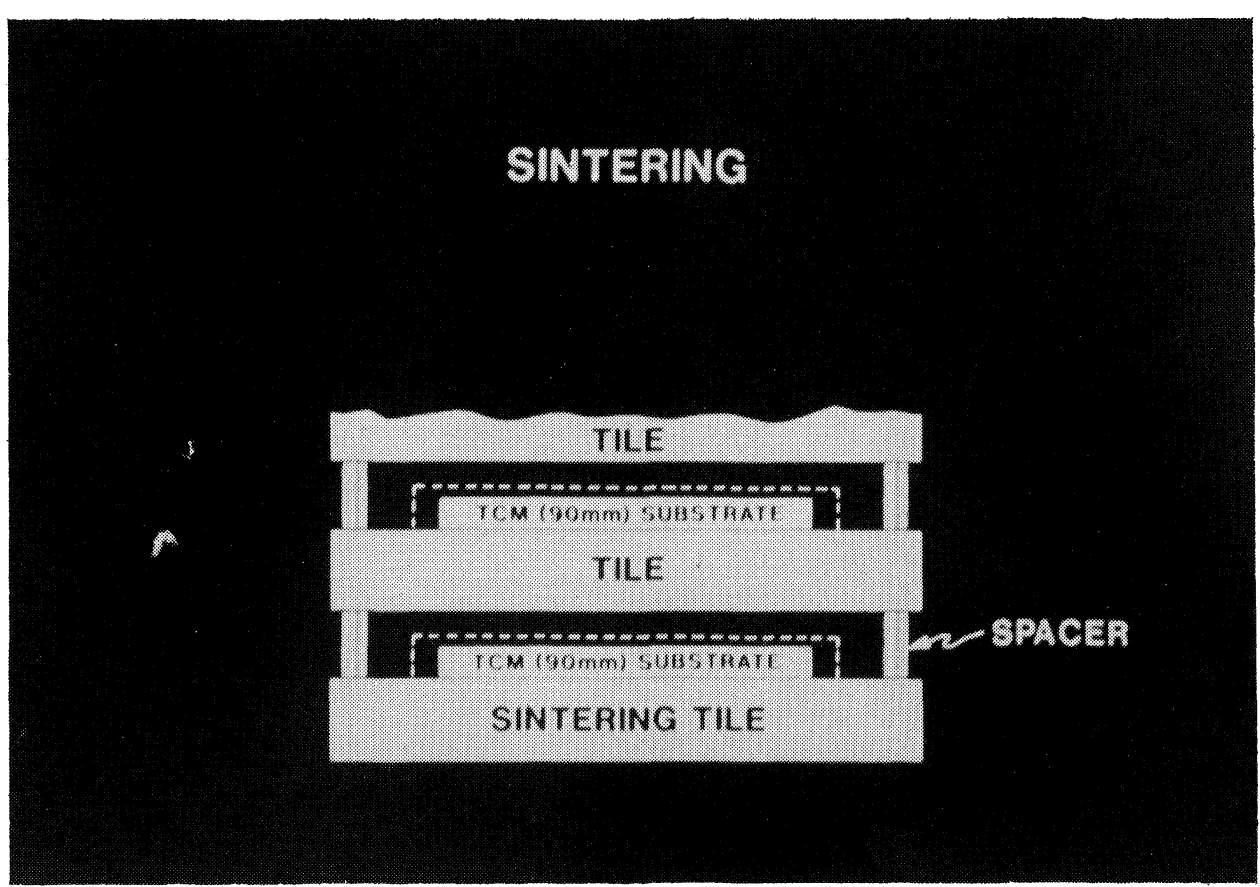

FIGURE 17 Sintering
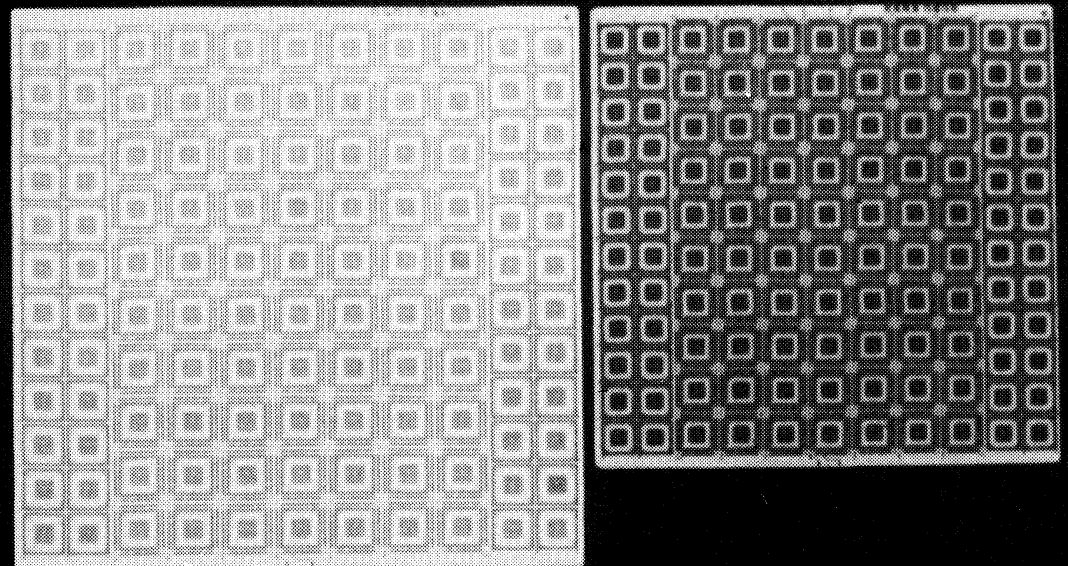

FIGURE 18 TCM substrate shrinkage 


\section{FINISHING AND TEST}

The final substrate process sector is finishing and test. As shown in Figure 19 the metal surfaces are plated to provide a wettable surface for chip solder connections and for brazing the $\mathrm{I} / \mathrm{O}$ pins and flange. Also, the pads surrounding each chip site are prepared for attachment of surface wires for altering internal substrate connections. Many process steps are required to prepare the surface and assure adequate control and cleanliness.

An electroless nickel bath was chosen that provides a low stress film. The bath was modified for selective plating of the metallurgy without depositing metal on the ceramic. This process is controlled to provide proper metal thickness and quality. The nickel plated substrate is then heat treated in a diffusion furnace to improve adhesion. After this procedure a thin gold layer is added to prevent formation of nickel oxide and improve wettability.

In the final plating process additional gold is deposited on the surface wiring pads around the periphery of each chip site. The plated surfaces are evaluated to guarantee high yield during module assembly processes, including chip joining and discrete wire bonding.

The substrates are electrically tested by probing the top surface pattern and I/O pads. Figure 20 shows the test used for checking the integrity of wiring routed from the C-4 pads to the discrete wiring pads around each chip site. Each substrate is then tested for internal layer signal and power connections as illustrated in Figure 21. Parametric testing is the final procedure that assures net resistance and capacitance are within specifications.

$\mathrm{I} / \mathrm{O}$ pin and flange brazing. illustrated in Figure 22, is the final substrate process. The pins and flange are plated to improve wettability during brazing. The braze was selected for corrosion resistance eliminating the need for protective organic coatings.

The completed substrate shown in Figure 23, with the pins and flange brazed in place, is ready for module assembly.

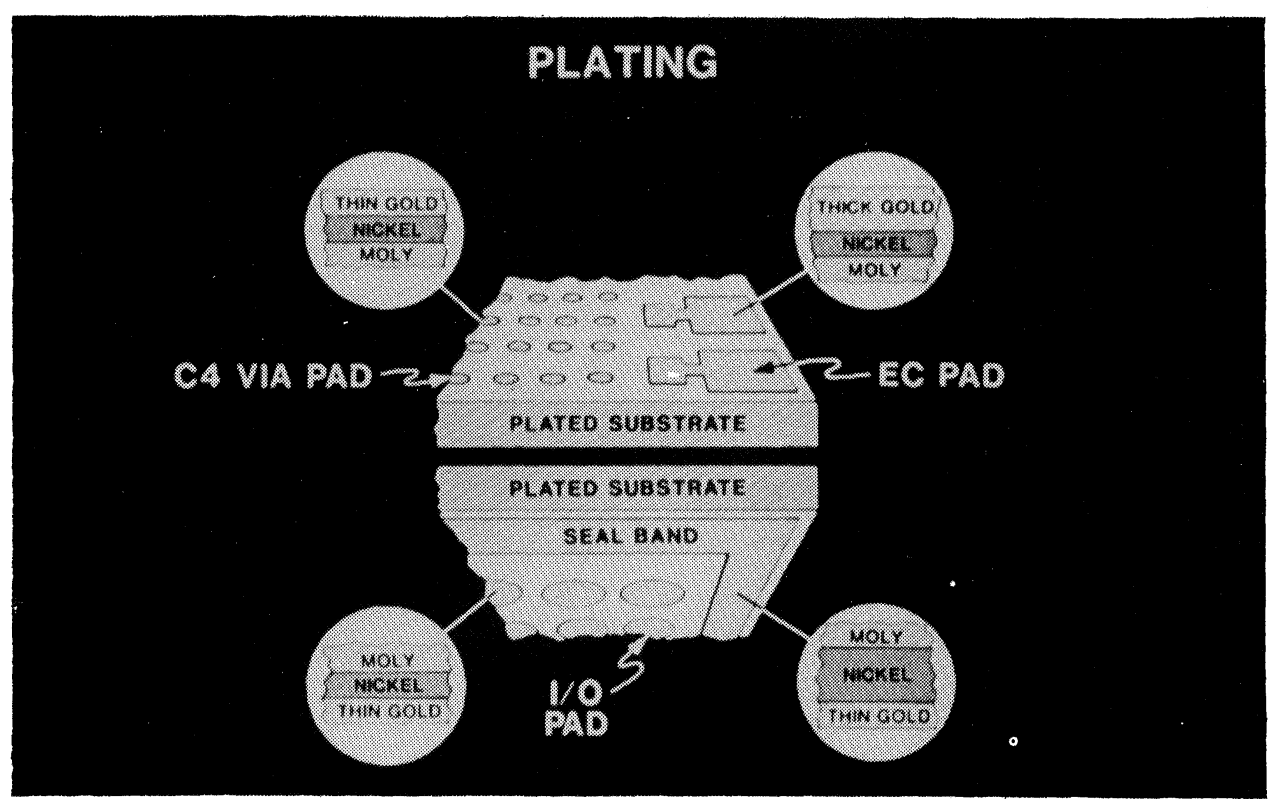

FIGURE 19 Plating 


\section{OPENS/SHORTS TESTINC}

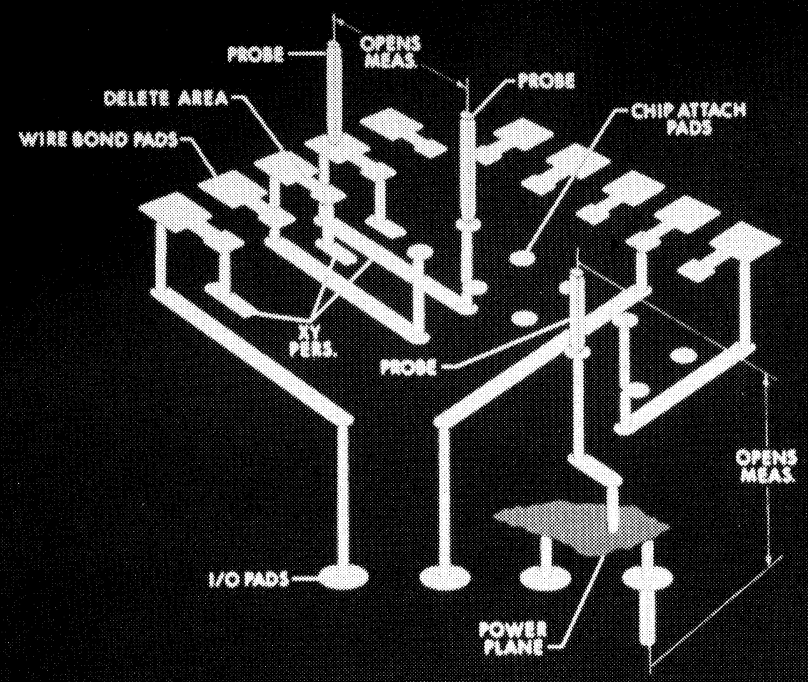

FIGURE 20 Open/shorts testing

\section{OPEN/SHORTS TESTING}

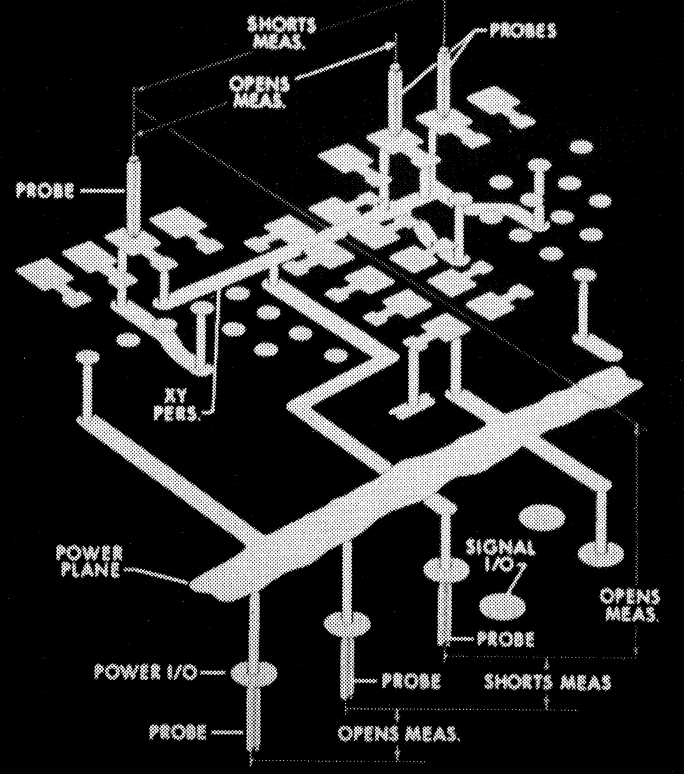

FIGURE 21 Open/shorts testing 


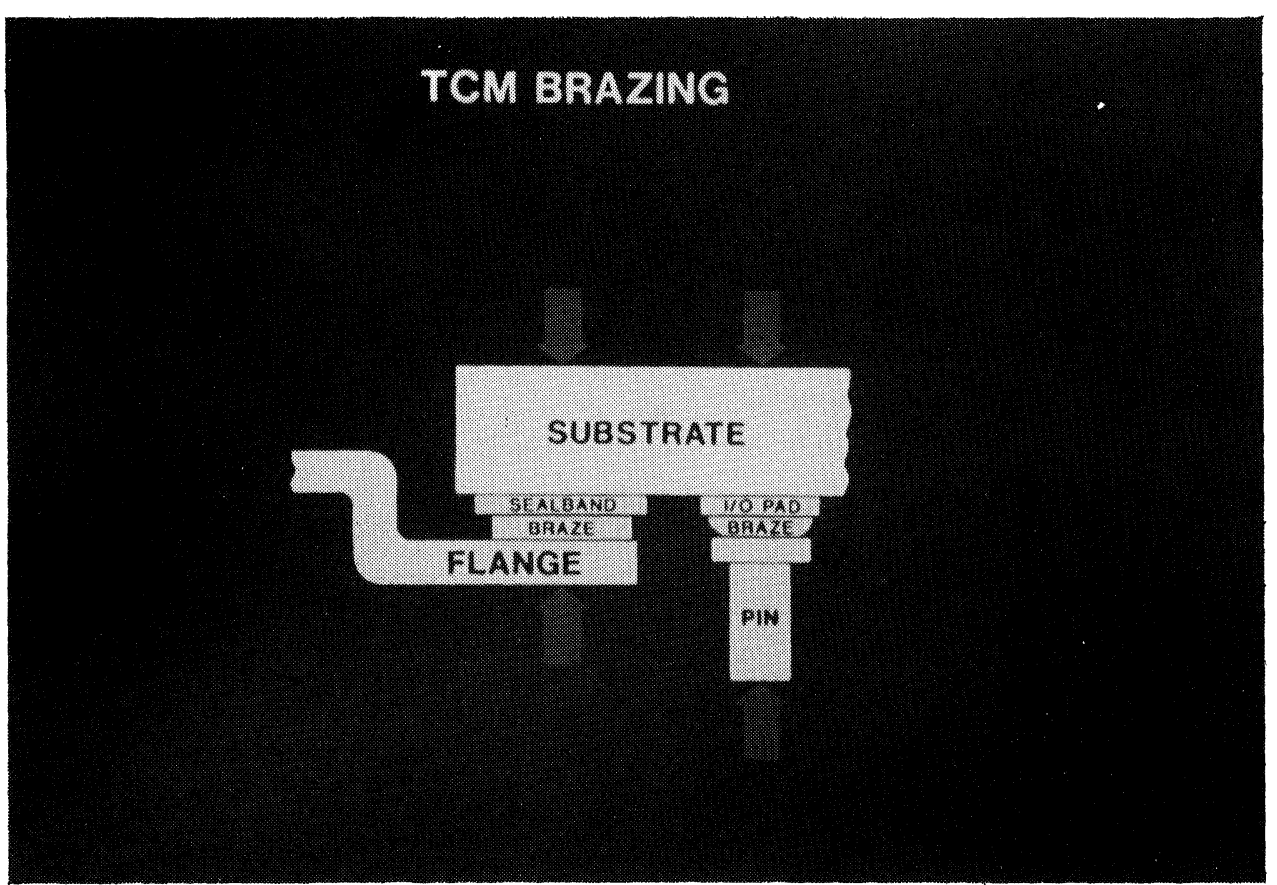

FIGURE 22 Brazing

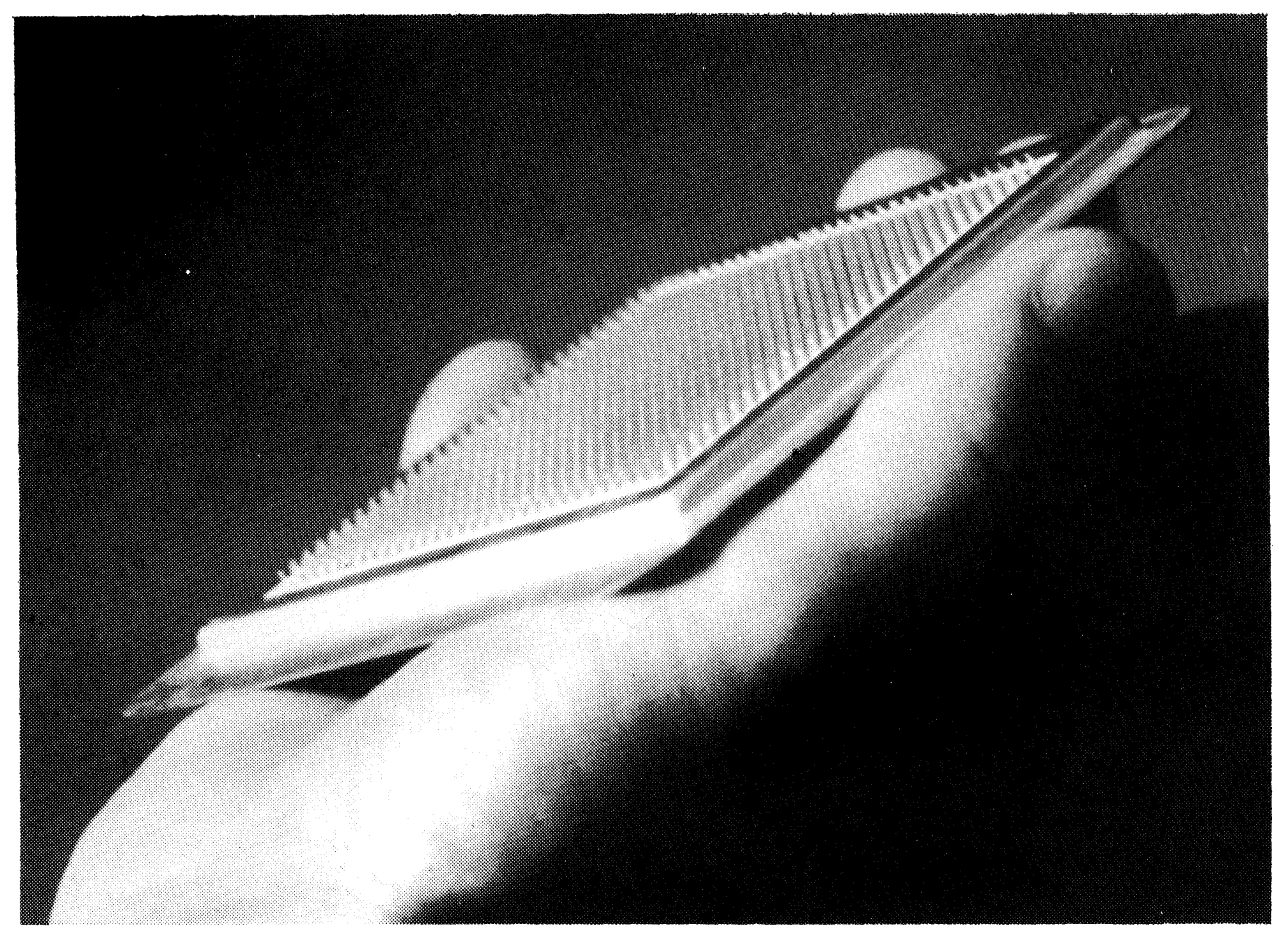

FIGURE 23 Completed TCM substrate 


\section{MODULE ASSEMBLY}

The module assembly sequence consists of chip joining, testing, chip rework and EC wiring, and mounting of the cover assembly.

The $\mathrm{C}-4$ technology is used to mount flip chips to the substrate surface. This joining technology is an extension of the $\mathrm{C}-4$ process first used in the IBM system $/ 360 .^{3,4} \mathrm{~A}$ flux improves wettability of the plated pads on the substrate surface. After positioning of up to 118 devices, each with 120 solder pads, all connections are made simultaneously in a nitrogen environment at an elevated temperature.

A chip-in-place test checks for chip to substrate connections. Power is applied to the assembly in a liquid dielectric bath and the $I / O$ pins and pads on the top surface are probed. After testing, chips can be removed if required and replaced by furnace reflow or a localized heat source.

The TCM is designed and fabricated to permit alterations in substrate wiring when they are required for engineering changes. Connections from surface wiring pads to internal wiring are deleted and surface wires are bonded in place to make the modified connections.

The TCM is completed by mounting the cooling housing using the $\mathrm{C}$-ring between the substrate flange and housing to form an airtight seal. Then, the assembly is charged with helium to a pressure of 1.6 atmospheres.

\section{MANUFACTURING CHALLENGES}

The TCM substrate and module assembly presented unique manufacturing challenges. The technologies required were completely new to volume manufacturing and the key challenge was to manage manufacturing build-up without an extensive historic data base. We can contrast this to semiconductors that have been in volume production for nearly 20 years and organic printed circuits that have a production history over an even longer period. Initial production was clearly "state of the art" which stressed the manufacturing line and emphasized the need to thoroughly understand the process and materials interactions and the process window limits.

Manufacture of the TCM to meet quality, volume, and throughput requirements demanded precise control of materials and processes and highly automated tooling. This is evident considering the inherent complexity of a multi-part number module that interconnects up to 118 LSI semiconductors and the close tolerances needed for successful automated manufacturing.

Some of the most significant actions in establishing a manufacturing capability were as follows:

- Material and process specification limits were established to control raw materials and other factors such as cast sheet drying conditions, screening and lamination parameters, and the sintering environment.

- Extensive analytical and statistical procedures were implemented to control material property limits.

- Tooling and controls were developed to guarantee fabrication within precise process limits.

- Facilities were designed to control contamination and the manufacturing environment.

- Complex computer-controlled electro-mechanical manufacturing equipment was designed for automated high speed handling and processing of substrate layers. 
- A data processing system was implemented to transmit design and logistical data to the tool controllers and to track work in process.

- A system was implemented to automatically inspect personalized ceramic sheets.

$\circ$ Test, chip positioning, and discrete wiring equipment was designed to take into account fired substrate dimensional variations.

\section{SUMMARY}

The technologies that were developed and implemented in manufacturing, together with a highly sophisticated tool system, provide a packaging capability that is extendable to future designs and supports further enhancements in LSI and VLSI semiconductors.

\section{ACKNOWLEDGEMENTS}

The authors acknowledge the efforts of many individuals who contributed to the multichip module technology both in development and manufacturing. The contributions extend over many years ${ }^{5,6}$ at IBM facilities in the United States, Germany and France.

\section{REFERENCES}

1. A.J. Blodgett, "A multilayer ceramic multi-chip module", Proceedings of the Electronics Components Conference, San Francisco, CA, 1980, pp. 283-285.

2. B.T. Clark and Y.M. Hill, "IBM multichip multilayer ceramic modules for LSI chips - designs for performance and density", IEEE Trans, Components, Hybrids, Manuf. Technol. CHMT-3, 89-93 (1980).

3. L.F. Miller, “Controlled collapse reflow chip joining”, IBM J. Res. Develop. 13, 239-250 (1969).

4. P.A. Totta and R.P. Sopher, "SLT device metallurgy and ITS monolithic extension", IBM J. Res. Develop. 13, 226-228 (1969).

5. B. Schwartz and D.L. Wilcox, "Laminated ceramics", Proceedings of the Electronics Components Conference, 17-26 (1967).

6. H.D. Kaiser, F.J. Pakulski and A.F. Schmeckenbecher, "A fabrication technique for multilayer ceramic modules", Solid State Technol. 00, 35-40 (May 1972). 

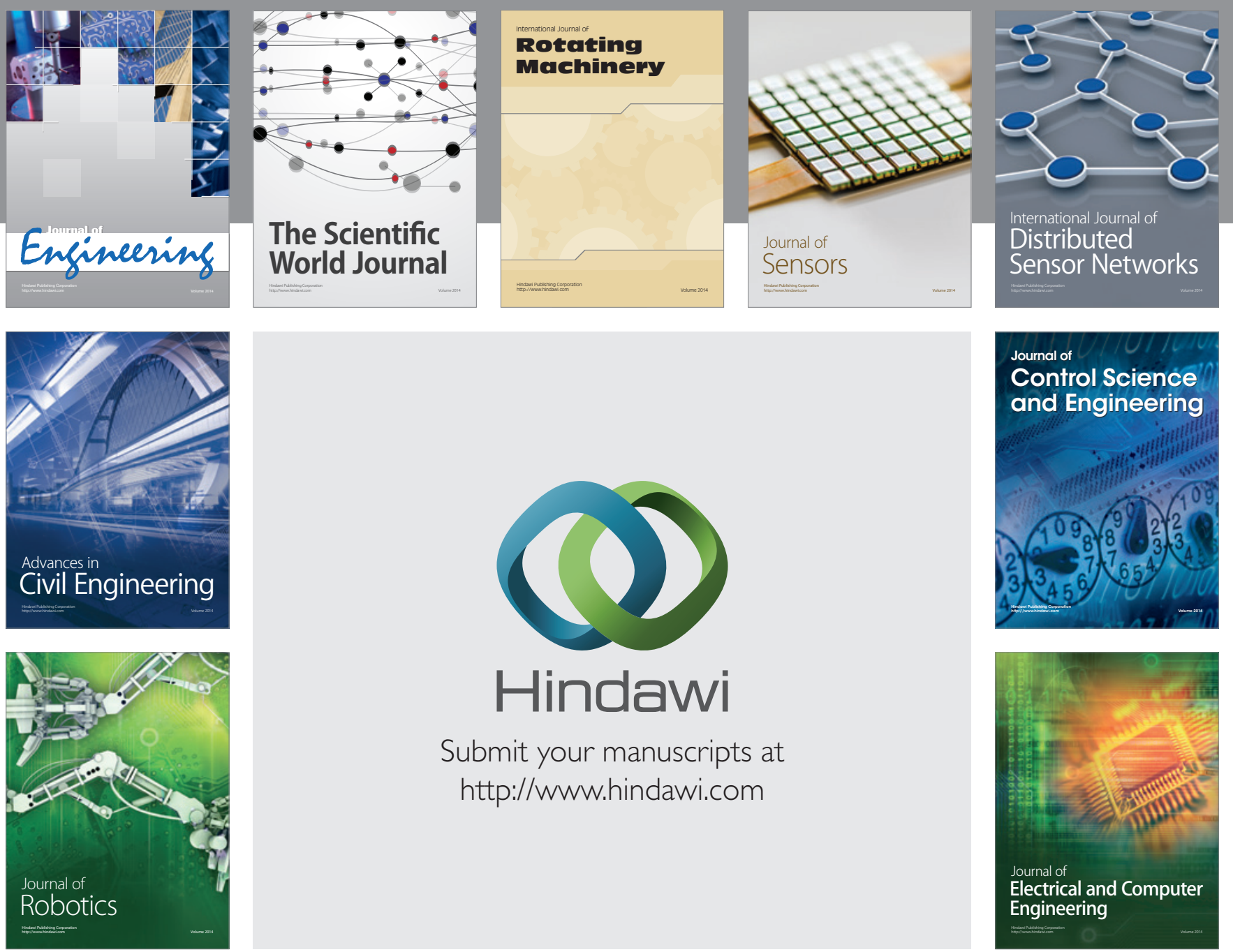

Submit your manuscripts at

http://www.hindawi.com
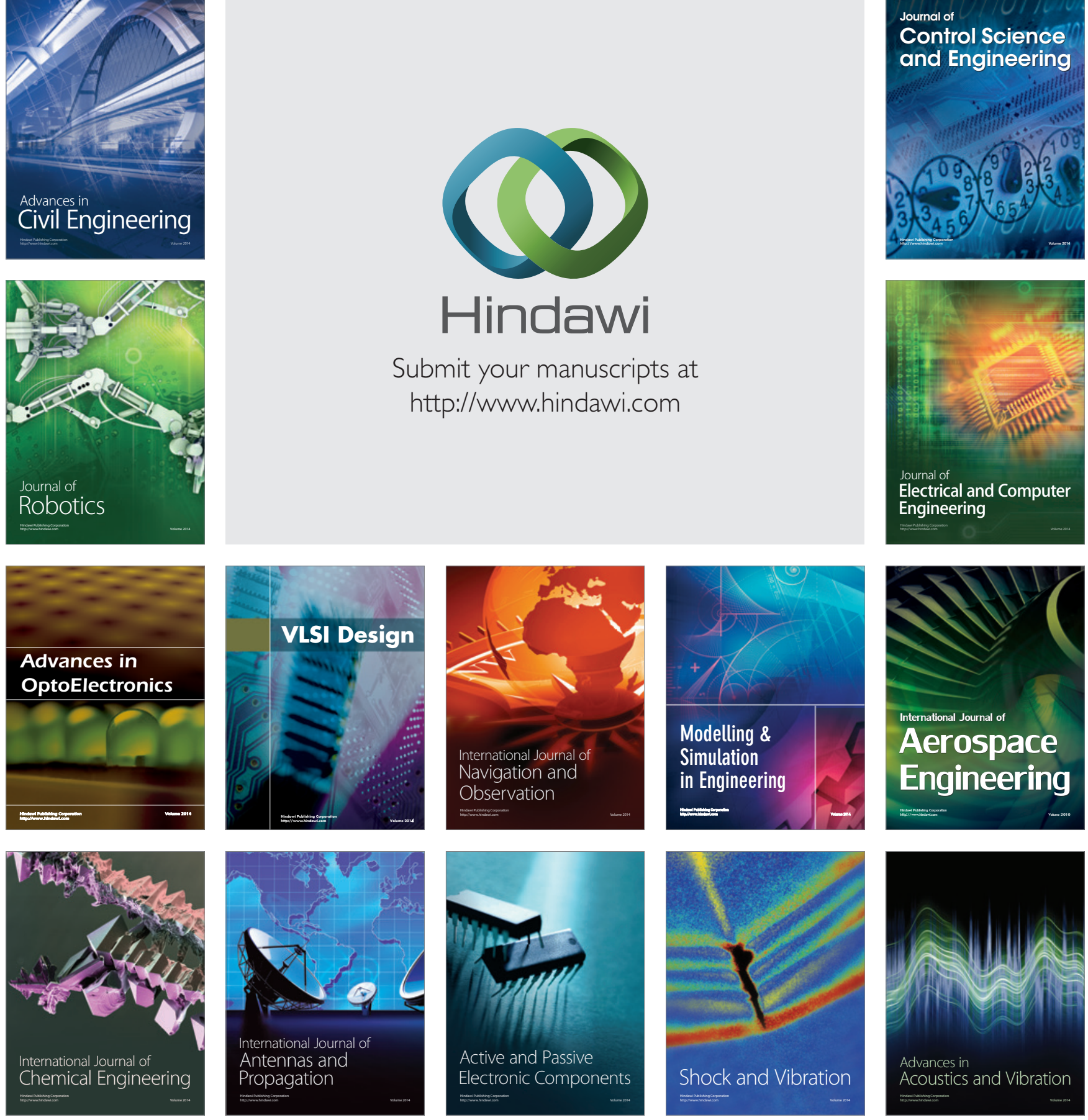